\title{
XVI Journées d'Études de Chimie sous Rayonnement
}

Realizaram-se, de 27 a 31 de maio de 2012, no Centro de Artes de Sines, as XVI Journées d'Études de Chimie sous Rayonnement (JECR 2012), com o apoio da Câmara Municipal de Sines e da Sociedade Portuguesa de Química, bem como de alguns patrocinadores nacionais e estrangeiros.

As JECR são um encontro francófono internacional em que participam cientistas de renome mundial na área da Química sob Radiação e suas aplicações. Este evento, bienal, realiza-se normalmente em França ou num país de língua oficial francesa, tendo sido a primeira vez, após cerca de 30 anos de existência, que teve lugar num país não francófono, continuando contudo o francês a ser a (única) língua oficial. A Química sob Radiação foi, como habitualmente, o tema do congresso, que teve uma duração de cinco dias, e foi constituído por conferências plenárias, comunicações orais e apresentações em painel, para além da componente social. As conferências plenárias introduziram os temas de cada uma das dez sessões de trabalho, que se estenderam desde os aspetos fundamentais e teóricos da Química sob Radiação, às aplicações biológicas e terapêuticas e à utilização da Radiação lonizante em áreas cada vez mais vastas e diversificadas a nível industrial, passando pelas Nanotecnologias e novos desenvolvimentos experimentais. Houve ainda uma sessão especial dedicada à comemoração do cinquentenário da descoberta do eletrão hidratado. Os títulos das conferências plenárias (e respetivos apresentadores) foram os seguintes: Histoire de la chimie sous rayonnement (António Nunes dos Santos, Portugal), Les électrons de basses énergies en milieux moléculaires et leurs applications en dosimétrie (Jean-Marc Jung, França), Oxydation des protéines: quel rôle la méthionine joue-t-elle? (Chantal Houée Levin, França), L'Électron solvaté: préhistoire et histoire (Jacqueline Belloni, França), Accident de Fukushima: passé, présent et perspectives (Barbara Pastina, Finlândia), Chimie dans le milieu interstellaire. Effets des rayonnements (Vincent Cobut, França), Facteur individuel en radiothérapie: comment on l'a oublié pendant un siècle (Nicolas Foray, França), Manipulation d'atomes et de molécules par électrons tunnels inélastiques avec le STM (Gérald Dujardin, França), Irradiation et radiolyse de glaces astrophysiques: le rôle des ions lourds dans le domaine keV-GeV (Herman Rothard, França) e La chimie sous

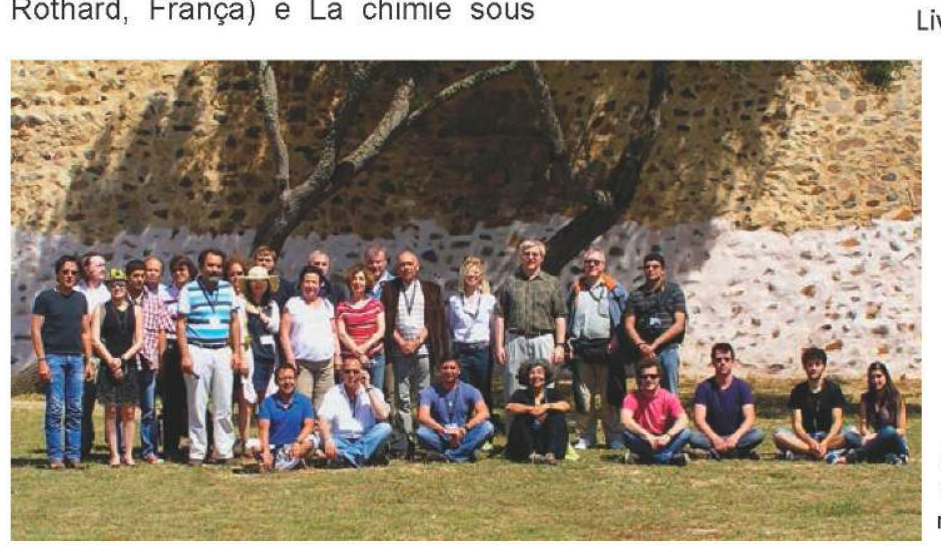

Fotografia de grupo dos participantes nas JECR 2012 rayonnement au XXlème siècle (James Wishart, E.U.A.).

O encontro contou com a participação de cerca de cinquenta congressistas, na sua maioria franceses, aos quais se juntou um grupo significativo de cientistas de Portugal, da Finlândia e dos Estados Unidos. Merece especial destaque a presença de muitos jovens investigadores, aliás uma das características e objetivo prioritário das JECR - divulgar os seus primeirabalhos e proporcionar o contacdesta área científica.

$\mathrm{Na}$ próxima edição, em 2014, as JECR regressam a França, onde serão organizadas na região de Biarritz-Soustons, por Vincent Cobut.

Abel Vieira (ajscv@fct.unl.pt) Membro da Comissão Científica e Presidente da Comissão Organizadora das JECR 2012

Pedro Santos (psantos@itn.pt) Livres da SPQ

\section{$6^{\text {Th }}$ Spanish-Portuguese-Japanese Organic Chemistry Symposium}

O $6^{\text {th }}$ Spanish-Portuguese-Japanese Organic Chemistry Symposium $\left(6^{\text {th }}\right.$ SPJ-OCS) decorreu na Faculdade de Ciências da Universidade de Lisboa (FCUL), de 18 a 20 de julho de 2012. Este Congresso faz parte de uma série de Encontros de Química Orgânica primeiramente organizados por Espanha e Japão, o primeiro dos quais teve lugar em Alicante em 1997.
Em seguida, de três em três anos, foi organizado alternadamente no Japão e em Espanha. Foi no ano de 2006 que, por iniciativa do Prof. Dr. José Cavaleiro, foi organizado o primeiro Congresso intitulado Spanish-Portuguese-Japanese Organic Chemistry Symposium. Depois de Osaka, onde decorreu $05^{\text {th }}$ SPJ-OCS, foi a FCUL que teve a primazia de receber os 200 participantes do $6^{\text {th }}$ SPJ-OCS, onde se incluem especialistas de Química Orgânica provenientes do meio académico e empresarial, sendo $63 \%$ dos participantes jovens investigadores e estudantes. Neste evento foram apresentados 126 posters e proferidas 24 conferências plenárias que versaram sobre variadas áreas em que a Química Orgânica tem um papel determi- 